\title{
Relationships among Attitude, Adoption and Satisfaction of News Media Users
}

\author{
Joon-Ho Lee1)
}

\begin{abstract}
The purpose of this study is to analyze contemporary news media usage patterns and satisfaction levels. More specifically, the study explored the attitudes and usage of news consumers in terms of four main media that supply the majority of news items and sources related to their traits. A survey was conducted using a sample of 390 respondents for empirical analysis. The following results and implications were found. First, users who gain news mainly through mobile devices or PCs perceive that Internet news media outlets have significantly greater relative advantages, compatibility, ease to use, triability, and observability than traditional news media users. Second, those who prefer and enjoy mobile news media are more likely to think of themselves as pursuers of more innovative technologies, services, and content than the other news media users. Third, news users are more satisfied with traditional media in terms of reliability and correctness dimensions, while being more satisfied with Internet media for convenience and rapidity dimensions. In conclusion, the competitive contemporary news supply system is evidence of a rapid change in news media consumption and a growing consumer divide between traditional and new forms of media.

Keywords: News Media, News Consumption, Media Use, Satisfaction, Adoption
\end{abstract}

\section{Introduction - Purpose of the Study}

The emergence and rapid adoption of the Internet since 2000 and of smart phones since 2010 have radically impacted the use, production, and distribution of news and news media. As of 2020, most people have adopted smart phones and PCs supported by high speed Internet services. This revolution of networks and devices, especially the widespread adoptions of mobile communication media, has changed nearly every way we process our individual and social life that includes our daily news consumption patterns.

Statistics and reports throughout Korea indicate that the traditional news media, newspaper and broadcasting, have become minor platforms for news content, whereas the new media represented by PCs and mobile devices have contributed to establishment of the major news platforms such as the internet portals, news applications, Youtube, and SNS. The readership of

Received(May 16, 2020), Review Result(1st: July 3, 2020, 2nd: August 21, 2020), Accepted(September 25, 2020)

1) (Professor) 47340 Department of Communication \& Media, Dong-eui Univ., Eomgwangno 176, Busanjin-gu, Busan, Korea

e-mail: joonlee@deu.ac.kr 
newspaper has fallen down below $20 \%$ in 2018. It is a remarkable trend when compared to a national readership of $80 \%$ in 2000 and $60 \%$ in 2010. Simultaneously, total news readership across all the media has been remained steady at around $80 \%$, with readers shifting to mobile news consumption increasing to over 60\%[1]. Subsequently, total advertising revenues for mobile media have increased to 3 trillion won with two-digit percents of average annual growth rates whereas the total of other more traditional media has decreased since 2015[2].

These phenomena are closely related to changes in news media consumption, production and distribution, content and format, and periodicity of reporting. It is becoming an abnormal life routine to read a printed newspaper during commuting time or to watch TV news at night. The first change has been the increasing use of mobile and social media with users reading and watching news on Facebook, Youtube, Naver, and Daum. Second, the number of news producers and distributors has increased tremendously. Anyone can now gather and write news and then report it to a plethora of media platforms, which in turn tend to generate 'fake' news content that lacks reliability or accuracy. Third, digital mobile media platforms have brought about changes in news content and formats. The tendency has been for news reporting to change from hard text to soft forms of multimedia news with the elimination of the inverted-pyramid news format. More and more traditional news suppliers that produce news separately now create content that is suited for the alternative but powerful platforms of Youtube and portals, and in so doing depend them for distribution. Fourth, since there are many outlets for newly produced and reported news, reporters and journalists face ever increasing competition and an environment that encourages them to make more updated news faster and for more users[3].

It is important to empirically explore how people consume news and gain satisfaction. In the new, fast changing environment of news media consumption, media users definitely have easier accesses to an increasing amount of news from diverse forms of news media. However, when choosing and accepting news media and content, the process becomes more complex. Therefore, this study analyzed characteristics of news media usage patterns in terms of selecting and adopting new media or new platforms. It also explored the relationships between real usage of news by users and their attitude toward different news media.

\section{Literature Review}

\subsection{Diffusion of Innovation}


The theory of diffusion of innovation explains how new technologies, ideas, or products are adopted by and disseminated to the general public. The term 'innovation' is defined as an idea, a technology, or a product that is perceived to be new by individuals or groups of adopting members, and 'diffusion' is defined as a process in which certain innovations are transmitted to and adopted by its members in a social system through certain communication channels[4]. Rogers proposed key factors that influence the process of innovation adoption and diffusion: (1) demographic characteristics of individuals; (2) perceived characteristics of innovations (relative advantage, compatibility, complexity, triability, observability); (3) innovativeness of individuals; and (4) communication channels (mass communication and interpersonal channels[5]. Among these factors, perceived characteristics of innovations and individual innovativness of adopters are considered the most relevant factors affecting individuals' news media selecting or adopting processes in this study.

\subsection{Uses and Gratifications}

In selecting media and content to consume, uses and gratifications approach characterizes media users as active and sufficiently motivated. It has been built for over fifty years based on two principles: (1) people are active in their selection of the media they consume, and (2) they are aware of their reasons for selecting media and content options. Since media technologies and services continuously proliferate, uses and gratifications research is more valuable than ever before in understanding the motivation of people when choosing media to consume and the gratifications they gain from the usage[6]. The theory assumes first that media users play an active role in selecting a medium or content, interpreting it, and integrating it into their lives. The second assumption is that different types of media compete against each other and against other sources of gratification (needs, wants, or satisfaction) for users' attention. The third theoretical assumption is that the medium that provides the most satisfaction for a person will be used more frequently than others.

In terms of motivation to use media and of gratification after using them, the following four dimensions are suggested: (1) 'cognitive' dimension, ie., news, documentaries, education, how-to videos; (2) 'affective' dimension, ie., comedies, variety shows, drama; (3) 'personal and social integrative or pressure' dimension, ie., Facebook, Twitter, YouTube, Social Network Service (SNS); (4) 'opportunistic and cost-effective' dimension, ie., advertising-free content, leisure time content, free trials[7][8]. 


\subsection{Technology Acceptance Model (TAM)}

User acceptance or adoption of new technologies and services has been a major interest of research for over three decades since late 1980s when a series of TAMs were proposed by Fred Davis. He originally conceptualized a model explaining system acceptance or rejection by users in organizations in order to enhance measure and prediction powers of research regarding new system or technology adoption and its actual use. As shown in [Fig. 2], he proposed a possible causal relationship among three variables: features and capabilities of a new system or technology (stimulus), user motivation to use the new system or technology (organism), and actual use of the new system or technology (response).

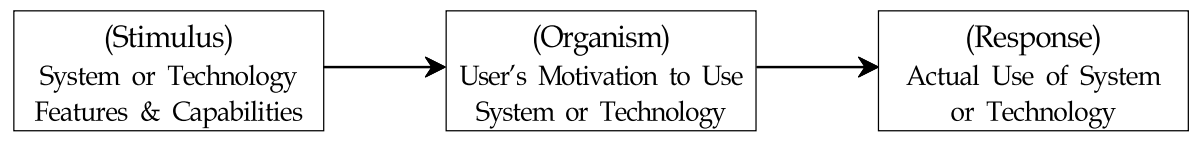

[Fig. 1] Conceptual Model for Technology Acceptance

Davis further refined his original conceptual model to suggest the first TAM ([Fig. 3]). In formulating this model he relied on the theory of reasoned action, the theory of planned behavior, and other related psychological research findings that dealt more with user's motivation. The variable of user motivation includes three sub-factors: perceived ease of use, perceived usefulness, and attitude toward using the new system or technology[9].

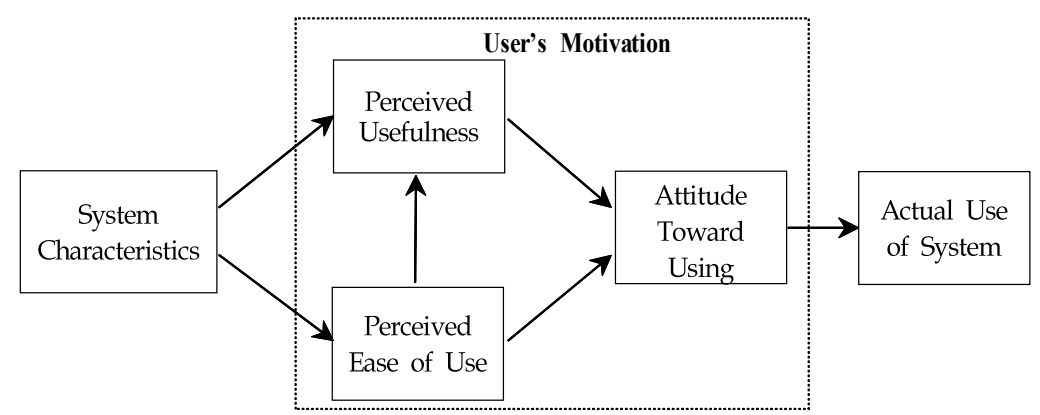

[Fig. 2] Original Technology Acceptance Model (TAM) (1986)

\subsection{Combined Theoretical Framework}

Several core elements and basic assumptions with a mixed theoretical basis were confirmed in the related studies[10]. Based on a meta-analysis study, the assumptions and frameworks of 
theories shown above need to be mixed into one with some modification to factors and their causal relationships mainly based on the the TAM structure[11]. Some factors in the uses and gratifications approach and a few key factors in the diffusion of innovation cannot be ignored in a new framework. These theoretical assumptions share an important common point: the autonomy and activeness of users are interdependent to explain the causal relationships throughout reaching the final step - 'continuous use of the media services.'

The following hybrid model was proposed using the prior theoretical frameworks described above ([Fig. 3]).

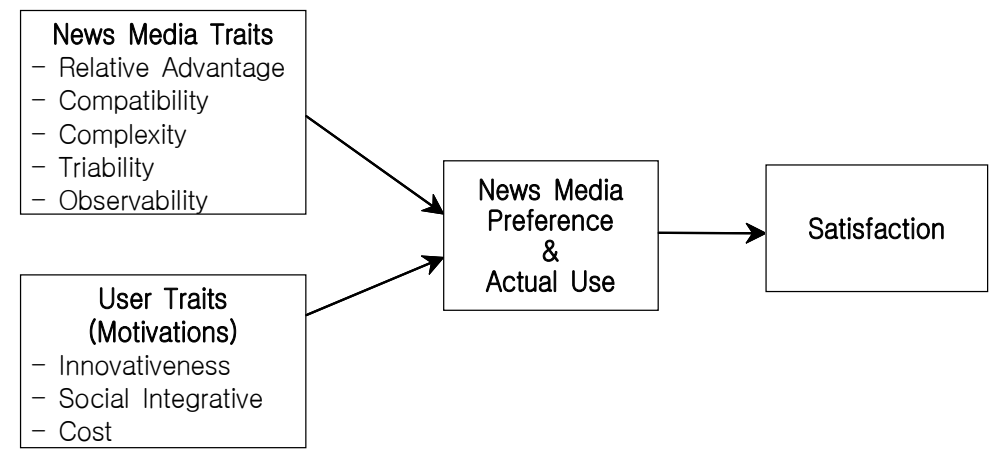

[Fig. 3] Hybrid News Media Usage Model for Analysis

\subsection{Research Question}

Although on-line news services are relatively new, they are familiar to people, and so there have been innumerable replication and verification studies conducted on this topic with findings collected using the three theoretical models and frameworks. However, these findings have been mostly variable and inconsistent. Therefore, it is necessary to analyze the proposed relationships based on a single unified combined model even though traditions among the theories are not the same. Based on the purpose of the study and the new theoretical framework, the following research questions are proposed.

$R Q$ 1. What is the relationship between users' perceived traits of news media and news media preference?

$\mathrm{RQ}$ 2. What is the relationship between users' motivation to use a particular form of news media and their news media preference?

RQ 3. What is the relationship between news media types and users' satisfaction? 


\section{Method}

This study used a random interview survey to collect useful data on news media usage and satisfaction patterns. A hybrid sampling method consisting of purposive sampling and stratified sampling was employed. Interviewers visited and asked those who had at minimum a smart phone and who had experience using on-line news with smart phones to answer questionnaires. Also, the sample consisted of the same numbers of males to females while controlling demographic characteristics such as age, education, and occupation, proportionately. The survey was conducted on October 2019 throughout the South-Eastern metropolitan areas of Korea. Total number of respondents was 400, however, 10 of them were excluded because they omitted answering an unacceptable number of essential questions.

A questionnaire consists five parts namely: (1) preference and uses of four news media broadcasting, newspaper, PC internet, mobile device; (2) perceived traits of each mediumrelative advantage, compatibility, complexity, triability, and observability; (3) motivations to use each news medium - innovativeness, social integrative, and cost; (4) satisfaction with news of each medium - reliability, fairness, correctness, depth, convenience, and rapidity; (5) demographics. To measure the second and the third question sets, three operationalized questions were designed for each variable. The internal consistency test confirming reliability of measurement resulted in high Cronbach's alpha indices over .78. Additionally, the 'satisfaction' is operationalized after a discussion with two other professors of journalism. They proposed the six virtues and values most contemporary news media need to have, and validated final questionnaire.

\section{Results}

To give solutions to the three research questions, a series of mean difference tests, including F-tests (Scheffe's multiple comperison) and t-tests (paired-sample) were performed to compare mean scores of different groups and variables. The highest number of respondents preferred using broadcasting news (TV and radio) as their main source of news ( $\mathrm{N}=187 ; 47.9 \%$ ). The second preferred news media were mobile devices ( $\mathrm{N}=103 ; 26.4 \%$ ). The third most preferred news media type was PC using the Internet $(\mathrm{N}=60 ; 15.4 \%)$. The least preferred news media were newspapers $(\mathrm{N}=40 ; 10.3 \%)$. Based on the news media preferences and frequencie of use, the respondents were divided into 4 groups and further analyzed. 
The RQ 1. examined the relationship between perceived news media traits and the media preference for actual use ([Table 1]). Those who obtained news through mobile devices, such as smart phones, mostly perceived that mobile news media gave the best relative advantages, compatibility, ease to use, triability, and observability. PC internet news users perceived that a PC is better for news consumption than is a newspaper or broadcasting media for the majority of aspects. Those who prefer TV or radio news evaluated broadcasting media higher than did newspaper readers in terms of relative advantage, compatibility, and complexity traits.

[Table 1] Relations between Perceived Traits of News Media and News Media Preference

\begin{tabular}{|c|c|c|c|c|c|}
\hline Media Traits & $\begin{array}{c}\text { News Media Preference } \\
\text { (Main News Source) }\end{array}$ & $\mathrm{N}$ & Mean & $\mathrm{SD}$ & $\begin{array}{l}\text { Mean Difference Test } \\
\text { F-value/Scheffe test }\end{array}$ \\
\hline \multirow{5}{*}{$\begin{array}{l}\text { Relative Advantage } \\
\text { - Better Functions }\end{array}$} & Broadcasting & 187 & 3.26 & .812 & \multirow{5}{*}{$\mathrm{M}>\mathrm{P}>\mathrm{B}>\mathrm{N}$} \\
\hline & Newspaper & 40 & 3.14 & .789 & \\
\hline & PC Internet & 60 & 3.43 & .660 & \\
\hline & Mobile Internet & 103 & 3.61 & .734 & \\
\hline & Total & 390 & 3.36 & .773 & \\
\hline \multirow{5}{*}{$\begin{array}{l}\text { Compatibility } \\
\text { - No Need to Learn } \\
\text { How to Use }\end{array}$} & Broadcasting & 187 & 3.27 & .821 & \multirow{5}{*}{$\begin{array}{c}8.621^{* * *} \\
\mathrm{M}>\mathrm{P}>\mathrm{B}>\mathrm{N}\end{array}$} \\
\hline & Newspaper & 40 & 3.02 & .838 & \\
\hline & PC Internet & 60 & 3.49 & .729 & \\
\hline & Mobile Internet & 103 & 3.80 & .739 & \\
\hline & Total & 390 & 3.40 & .802 & \\
\hline \multirow{5}{*}{$\begin{array}{l}\text { Complexity } \\
\text { - Difficult to Use }\end{array}$} & Broadcasting & 187 & 3.07 & .947 & \multirow{5}{*}{$\begin{array}{c}4.932^{* *} \\
\mathrm{~N}>\mathrm{P}>\mathrm{B}>\mathrm{M}\end{array}$} \\
\hline & Newspaper & 40 & 3.49 & .941 & \\
\hline & PC Internet & 60 & 3.28 & .818 & \\
\hline & Mobile Internet & 103 & 2.88 & .879 & \\
\hline & Total & 390 & 3.20 & .925 & \\
\hline \multirow{5}{*}{$\begin{array}{l}\text { Triablity } \\
\text { - Can Try Anytime, } \\
\text { Anywhere }\end{array}$} & Broadcasting & 187 & 3.21 & .909 & \multirow{5}{*}{$\begin{array}{c}6.994^{* * *} \\
M>P=B=N\end{array}$} \\
\hline & Newspaper & 40 & 3.19 & .846 & \\
\hline & PC Internet & 60 & 3.24 & .724 & \\
\hline & Mobile Internet & 103 & 3.78 & .673 & \\
\hline & Total & 390 & 3.41 & .838 & \\
\hline \multirow{5}{*}{$\begin{array}{l}\text { Observability } \\
\text { - Can See Many } \\
\text { Others Use }\end{array}$} & Broadcasting & 187 & 3.28 & .932 & \multirow{5}{*}{$8.507^{* * *}$} \\
\hline & Newspaper & 40 & 3.25 & .937 & \\
\hline & PC Internet & 60 & 3.63 & .804 & \\
\hline & Mobile Internet & 103 & 3.89 & .790 & \\
\hline & Total & 390 & 3.49 & .900 & \\
\hline
\end{tabular}

${ }^{*} \mathrm{p}<.05,{ }^{* *} \mathrm{p}<.011^{* * *} \mathrm{p}<.001,{ }^{n s}$ no significance

[Table 2] shows the result of mean difference tests giving answers to the RQ 2. The table presents analyses of relationships between motivations to use and media preference for actual use. In terms of 'innovativeness,' the users who prefer and enjoy mobile media news are most likely to think of themselves as persuers of new innovative technologies, services, and content. The second most innovative system pursuers are PC internet news users, who like to adopt 
more innovative media and services than traditional news media users. However, in terms of 'social integrative' and 'perceived cost' dimensions, there is no significant difference among the groups of news media preferences and actual uses.

[Table 2] Relations between Motivations to Use News Media and News Media Preference

\begin{tabular}{|c|c|c|c|c|c|}
\hline $\begin{array}{c}\text { User Traits } \\
\text { (Motivations) }\end{array}$ & $\begin{array}{c}\text { News Media Preference } \\
\text { (Main News Source) }\end{array}$ & $\mathrm{N}$ & Mean & $\mathrm{SD}$ & $\begin{array}{c}\text { Mean Difference Test } \\
\text { F-value/Scheffe test }\end{array}$ \\
\hline \multirow{5}{*}{$\begin{array}{l}\text { Innovativeness } \\
\text {-Technology } \\
\text {-Service } \\
\text {-Content }\end{array}$} & Broadcasting & 187 & 2.77 & .709 & \multirow{5}{*}{$\begin{array}{c}10.402^{* * *} \\
\mathrm{M}>\mathrm{P}>\mathrm{N}=\mathrm{B}\end{array}$} \\
\hline & Newspaper & 40 & 2.80 & .676 & \\
\hline & PC Internet & 60 & 3.01 & .419 & \\
\hline & Mobile Internet & 103 & 3.25 & .590 & \\
\hline & Total & 390 & 2.90 & .659 & \\
\hline \multirow{5}{*}{$\begin{array}{l}\text { Social Integrative } \\
\text {-Social Influence } \\
\text {-Social Relation } \\
\text {-Social Pressure }\end{array}$} & Broadcasting & 187 & 3.40 & .708 & \multirow{5}{*}{$1.467^{n s}$} \\
\hline & Newspaper & 40 & 3.43 & .809 & \\
\hline & PC Internet & 60 & 3.32 & .528 & \\
\hline & Mobile Internet & 103 & 3.41 & .680 & \\
\hline & Total & 390 & 3.39 & .689 & \\
\hline \multirow{5}{*}{$\begin{array}{l}\text { Perceived Cost } \\
\text {-Subscription Fee } \\
\text {-Additional Cost } \\
\text {-Advertisement }\end{array}$} & Broadcasting & 187 & 3.42 & .720 & \multirow{5}{*}{$1.471^{n s}$} \\
\hline & Newspaper & 40 & 3.40 & .821 & \\
\hline & PC Internet & 60 & 3.29 & .522 & \\
\hline & Mobile Internet & 103 & 3.36 & .681 & \\
\hline & Total & 414 & 3.38 & .693 & \\
\hline
\end{tabular}

The third research question of the study was "What is the relationship between news media types and user's gained satisfaction?" This is to explore how does the satisfaction level of each news medium differ from each other in six different satisfaction dimensions. The results of this question are shown in [Table 3].

First, after comparing each news medium's satisfaction level of 'reliability,' it was found that traditional media, such as broadcasting and newspaper, had significantly higher mean values than the new, Internet media. This may have resulted from the fact that the editing process in traditional news media has been more complex and stricter. Second, newspapers are thought to be unfair when compared to the other news media. This seems to come from the fact that most newspapers in democratic societies have the highest degree of freedom and show their own standpoint of interests. The third dimension of satisfaction is 'correctness.' Broadcast news was evaluated to be most accurate by the majority of respondents. This may be true because most broadcasters are subject to media regulation with its high degree of responsibility and penalties regarding the truth of the medium's messages. Fourth, broadcast news was thought to be the most unsatisfactory in terms of its 'depth' of news because it is very difficult for broadcasters to secure sufficient running time for in-depth news reporting. Fifth, in terms of 

'convenience' for using news, mobile media were considered the most satisfactory, followed by PC Internet usage, broadcasting, and newspaper, in order. It is possible that people feel easier and more casual when getting news from mobile and connected media, rather than fixed, hard-to-carry media. Finally, those media which utilize Internet connections were perceived to provide higher satisfaction levels in term of 'rapidity.' This seems a natural result, considering the technological differences among the media.

[Table 3] Relations between News Media Preference and Satisfaction

\begin{tabular}{|c|c|c|c|c|c|}
\hline $\begin{array}{l}\text { Satisfaction } \\
\text { Dimension }\end{array}$ & News Media & $\mathrm{N}$ & Mean & SD & $\begin{array}{l}\text { paired t-test } \\
(\mathrm{p}<.05)\end{array}$ \\
\hline \multirow{4}{*}{ Reliability } & Broadcasting & \multirow{4}{*}{382} & 2.54 & .932 & \multirow{4}{*}{$\mathrm{B}=\mathrm{N}>\mathrm{M}=\mathrm{P}$} \\
\hline & Newspaper & & 2.57 & .748 & \\
\hline & PC Internet & & 2.03 & .699 & \\
\hline & Mobile Internet & & 2.16 & .880 & \\
\hline \multirow{4}{*}{ Fairness } & Broadcasting & \multirow{4}{*}{384} & 2.72 & .676 & \multirow{4}{*}{$\mathrm{B}=\mathrm{P}=\mathrm{M}>\mathrm{N}$} \\
\hline & Newspaper & & 2.35 & 1.027 & \\
\hline & PC Internet & & 2.66 & .498 & \\
\hline & Mobile Internet & & 2.64 & .896 & \\
\hline \multirow{4}{*}{ Correctness } & Broadcasting & \multirow{4}{*}{380} & 2.91 & .993 & \multirow{4}{*}{$\mathrm{B}>\mathrm{N}=\mathrm{M}>\mathrm{P}$} \\
\hline & Newspaper & & 2.47 & .789 & \\
\hline & PC Internet & & 2.24 & .870 & \\
\hline & Mobile Internet & & 2.44 & .751 & \\
\hline \multirow{4}{*}{ Depth } & Broadcasting & \multirow{4}{*}{379} & 2.37 & 1.184 & \multirow{4}{*}{$\mathrm{M}=\mathrm{N}=\mathrm{P}>\mathrm{B}$} \\
\hline & Newspaper & & 3.38 & .965 & \\
\hline & PC Internet & & 3.33 & .919 & \\
\hline & Mobile Internet & & 3.39 & 1.010 & \\
\hline \multirow{4}{*}{ Convenience } & Broadcasting & \multirow{4}{*}{386} & 2.61 & 1.049 & \multirow{4}{*}{$\mathrm{M}>\mathrm{P}>\mathrm{B}>\mathrm{N}$} \\
\hline & Newspaper & & 2.21 & .897 & \\
\hline & PC Internet & & 3.45 & .743 & \\
\hline & Mobile Internet & & 3.60 & .984 & \\
\hline \multirow{4}{*}{ Rapidity } & Broadcasting & \multirow{4}{*}{388} & 3.13 & .852 & \multirow{4}{*}{$\mathrm{M}=\mathrm{P}>\mathrm{B}=\mathrm{N}$} \\
\hline & Newspaper & & 3.08 & 1.569 & \\
\hline & PC Internet & & 3.39 & .241 & \\
\hline & Mobile Internet & & 3.41 & .529 & \\
\hline
\end{tabular}

\section{Conclusion}

Mass media news-seeking had been and continues to be an important process by which each medium competes to secure a significant portion of users. News consumers try and adopt their most preferred news source among the competing media. Based on the research findings, the consumers tend to choose their primary favorite news media and sources depending on how they perceive the traits of each medium, innovativeness of the media platform, and satisfaction 
level provided. The four different forms of news media compete as substitutes in a variety of aspect of media traits and user motivations. Especially, innovativeness has led to superiority of mobile and PC Internet news media. Furthermore, they seem to severely compete as supplements in terms of user satisfaction dimensions. The competitive modern news supply system reflects rapid changes in news media consumption behavior and a growing division between traditional media and the new, Internet-based media favorites.

The current research remains incomplete until subsequent specific empirical studies will clearly explore the causality of relationships among the traits of news media, the motivation of users, real news media adoptions, and the satisfaction levels of users that were suggested in the research framework of this study. Furthermore, it will be a point of interest to generate predictions in how the news media co-evolve in this highly competitive market.

\section{References}

[1] Korean Communications Commission, Annual Research of Broadcast Media Usage Patterns, https://portal.kocca.kr/portal/bbs/view/B0000204/1940856.do?menuNo=200247\&categorys=4\&subcate $=58 \& c a t e C o$ $\mathrm{de}=0 \#$, June 18 (2019)

[2] http://blog.newswire.co.kr/, Jun 18 (2020)

[3] http://newsmapping.com/, Jun 26 (2020)

[4] E. M. Rogers, Diffusion of Innovations, $4^{\text {th }}$ ed. USA New York, NY: Free Press, (1995)

[5] E. M. Rogers, Diffusion of Innovations, $5^{\text {th }}$ ed. USA New York, NY: Free Press, (1995)

[6] V. Cynthia, What is Uses and Gratifications Theory? Definition and Examples, Thought Co., https://www.thoughtco.com/uses-and-gratifications-theory-4628333, May 17 (2020)

[7] http://www.communicationstudies.com/communication-theories/uses-and-gratifications-theory/, May 14 (2020)

[8] J. H. Lee, C. H. Park, Uses and Gratification of Non-terrestrial TV Media and Their Competition: The Case of College Students, Journal of Broadcasting \& Telecommunications Research, (2001), Vol.53, pp.221-256.

[9] F. Davis, A Technology Acceptance Model for Empirically Testing New End-User Information Systems: Theory and Results, Doctoral Dissertation, MIT Sloan School of Management, Cambridge, MA, (1986)

[10] S. S Han, H. Yu, D. H. Shin, Explicating Motivations \& Attitudes Affecting the Persistent Intention to Adopt Binge-Watching, Journal of Korea Contents Association, (2017), Vol.17, No.2, pp.521-534.

[11] J. H. Lee, What Affects Satisfaction and Continuous Usage Intention of On-Line Video Service Users? Proceedings of Annual Convention of Future Convergence Technology Research Society, (2020) June 27; Daejeon, Korea 